\title{
Ability of a land surface model to predict climate induced changes in northern Russian river runoff during the 21st century
}

\author{
O. N. Nasonova ${ }^{1}$, Y. M. Gusev ${ }^{1}$, E. M. Volodin ${ }^{2}$, and E. E. Kovalev ${ }^{1}$ \\ ${ }^{1}$ Institute of Water Problems, Russian Academy of Sciences, Moscow, Russia \\ ${ }^{2}$ Institute of Numerical Mathematic, Russian Academy of Sciences, Moscow, Russia \\ Correspondence to: O. N. Nasonova (nasonova@aqua.laser.ru)
}

Received: 11 March 2015 - Accepted: 11 March 2015 - Published: 12 June 2015

\begin{abstract}
The objective of the present study is application of the land surface model SWAP to project climate change impact on northern Russian river runoff up to 2100 using meteorological projections from the atmosphere-ocean global climate model INMCM4.0. The study was performed for the Northern Dvina River and the Kolyma River characterized by different climatic conditions. The ability of both models to reproduce the observed river runoff was investigated. To apply SWAP for hydrological projections, the robustness of the model was evaluated. The river runoff projections up to 2100 were calculated for two greenhouse gas emission scenarios: RCP8.5 and RCP4.5 prepared for the phase five of the Coupled Model Intercomparison Project (CMIP5). For each scenario, several runoff projections were obtained using different models (INMCM4.0 and SWAP) and different post-processing techniques for correcting biases in meteorological forcing data. Differences among the runoff projections obtained for the same emission scenario and the same period illustrate uncertainties resulted from application of different models and bias-correcting techniques.
\end{abstract}

\section{Introduction}

Nowadays atmosphere-ocean global climate models (AOGCMs) represent the main tool for physically based assessments of future climate change which can be used for hydrological projections. The hydrological projections can be done directly by AOGCMs coupled with river routing models to obtain streamflow at a river basin outlet. This is widely used for evaluating the performance of GCMs and for studying the climate change impact on water resources of large river basins (e.g. Miller and Russell, 1992; Arora and Boer, 2001; Liston et al., 1994). Comparison of runoff hydrographs simulated by GCMs with observed ones (e.g. Arora et al., 2001; Nohara et al., 2006) shows a poor agreement. The major reasons seem to be a coarse spatial scale of GCMs and large errors in modelling precipitation and partitioning precipitation between evapotranspiration and runoff. The alternative approach to direct application of GCMs for runoff projections is application of their outputs to force hydrological models (HMs) or land surface models
(LSMs). For a large river basin or catchment, meteorological outputs can be used directly, while for smaller ones spatial downscaling and disaggregation techniques are used (Arora and Boer, 2001).

In these two approaches a flow routing scheme, as well as HMs and LSMs can also contribute to the accuracy of hydrograph simulation, however, as it was shown in a number of publications (e.g. Arora et al., 2001; Gosling et al., 2011) this contribution is much smaller as compared to that from a GCM. To reduce biases and uncertainties of any individual GSM, a weighted ensemble mean is suggested to use for multimodel projections (Nohara et al., 2006).

In this study the above two approaches: (1) direct application of AOGCM for runoff projections and (2) application of meteorological outputs from AOGCM to force LSM's runoff simulation are used. The objectives of the study are: (1) investigating the possibility of application of the LSM SWAP (Soil Water - Atmosphere - Plants) (Gusev and Nasonova, 2003, 2004, 2010) for projecting changes in northern river runoff due to possible climate change, and (2) evaluating the 

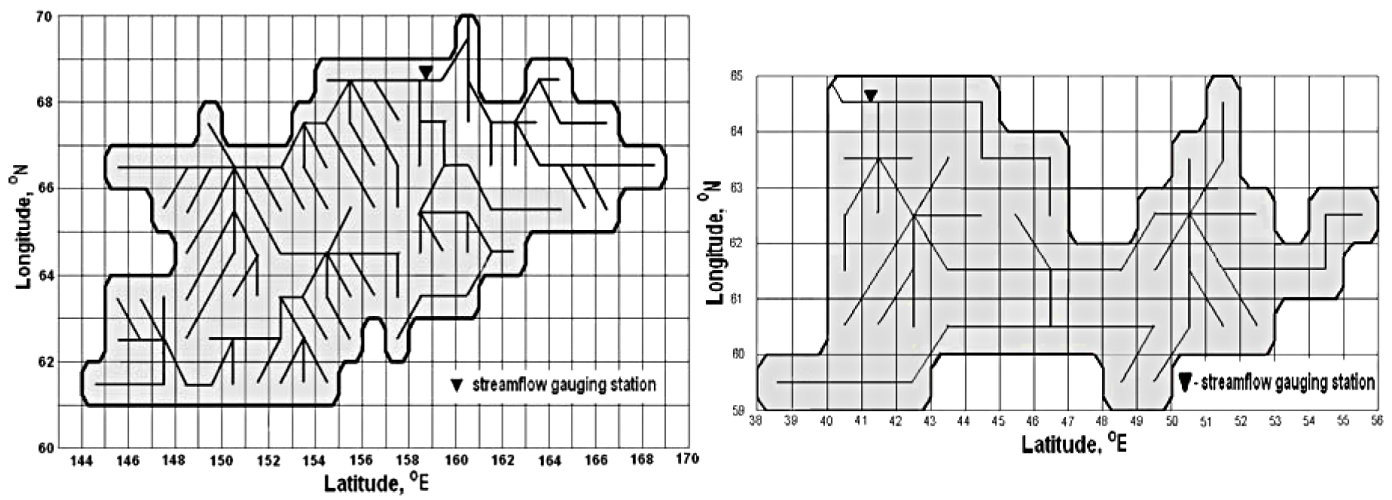

Figure 1. Schematization of the Kolyma (left panel) and the Northern Dvina (right panel) river basins.

uncertainties in river runoff projections resulted from the application of different types of models (AOGCM and LSM) and different bias-correcting techniques for meteorological projections. Here, AOGCM INMCM4.0 (Institute of Numerical Mathematic Climate Model, version 4.0) (Volodin et al., 2010) will be used.

\section{Methodology}

\subsection{Study area}

The Northern Dvina and the Kolyma river basins located within the pan-Arctic basin and characterized by different natural conditions were chosen for the study. The Northern Dvina River basin (area: $357000 \mathrm{~km}^{2}$ ) is situated on the north of the European part of Russia. Typical features of the basin are excessive wetness (mean annual precipitation varies from $650 \mathrm{~mm}$ in the north to $800 \mathrm{~mm}$ in the southwest, while mean annual potential evaporation is within the range of $400-500 \mathrm{~mm} ; 65-70 \%$ of precipitation falls during the warm season), low solar radiation, impact of northern seas, and relatively uniform natural conditions. Air masses from the Atlantic Ocean generally mitigate the climate. The combination of these factors results in a short (3-4 months) and cool summer with mean July temperature equaled to 14$17^{\circ} \mathrm{C}$ and a long (5-6 months) and cold winter with mean January air temperature from -13 to $-15^{\circ} \mathrm{C}$. The mean annual runoff at the basin outlet is $309 \mathrm{~mm}$. Forests (mostly coniferous) occupy nearly $80 \%$ of the basin.

The Kolyma River basin (area: $644000 \mathrm{~km}^{2}$ ) is located in the north-eastern part of Siberia mainly in the subarctic zone, while its northern parts are in the arctic zone. The main features of this region are extremely low winter temperatures and permafrost. Mean January air temperature varies from -30 to $-42{ }^{\circ} \mathrm{C}$ (minimal values reach -50 to $-68^{\circ} \mathrm{C}$ ) in different parts of the basin. Mean July air temperature is 10 $14^{\circ} \mathrm{C}$. Mean annual precipitation increases from $150 \mathrm{~mm}$ in the northern part of the basin to $250-300 \mathrm{~mm}$ southward and up to $500-600 \mathrm{~mm}$ in the mountainous area. Nearly $65-75 \%$ of precipitation falls during the summer months. The mean annual runoff at the basin outlet is $190 \mathrm{~mm}$. Sparse coniferous forests and tundra are prevalent in the basin.

Figure 1 shows schematization of the two river basins using $1^{\circ} \times 1^{\circ}$ TRIP (Total Runoff Integrating Pathways) scheme (Oki and Sud, 1998).

\subsection{Models}

Two models were used for runoff simulation: AOGCM INMCM4.0 and LSM SWAP. Both models reproduce runoff at each calculational grid cell. To obtain streamflow at a basin outlet a river routing model (RRM) was used.

\subsubsection{INMCM4.0 model}

The INMCM4.0 model (Volodin et al., 2010) consists of two major blocks representing a model of general circulation of the atmosphere (with spatial resolution in longitude and latitude $2^{\circ} \times 1.5^{\circ}$ ) and a model of general circulation of the ocean $\left(1^{\circ} \times 0.5^{\circ}\right)$.

The INMCM4.0 has participated in a number of international projects, such as Atmospheric Model Intercomparison Project (AMIP) and Coupled Model Intercomparison Project (CMIP), designed for comparison of GCMs developed by modelling groups in different countries with each other and with observational data. The general conclusion made from the analysis of the obtained results is that the INMCM4.0 by its quality is among the best up-to-date AOGCMs.

\subsubsection{SWAP model}

The land surface model SWAP is a spatially distributed physically-based model (here, one-degree spatial resolution is used) describing the processes of heat and water exchange within a soil-vegetation/snow cover-atmosphere system (SVAS). Different versions of SWAP and the results of their validation were detailed in a number of publications (e.g. Gusev and Nasonova, 2003, 2004, 2010). The results of model validation have demonstrated that SWAP adequately 
reproduces heat and water exchange processes occurring in SVAS.

The last version of SWAP treats the following processes: interception of liquid and solid precipitation by vegetation; evaporation, melting and freezing of intercepted precipitation, including refreezing of melt water; formation of snow cover at the forest floor and at the open site; partitioning of non-intercepted precipitation or water yield of snow cover between surface runoff and infiltration into a soil; formation of the water balance of aeration zone including transpiration, soil evaporation, water exchange with underneath layers and dynamics of soil water storage; water table dynamics; formation of the heat balance and thermal regime of SVAS; soil freezing and thawing.

\subsubsection{River routing model}

Runoff modelled by INMCM4.0 or SWAP for each grid box was then transformed by a river routing model. Such a transformation may be performed by different ways. Herein, a simple linear transfer model in river channels was used (Kanae et al., 1995). The RRM operated in a coupled mode with SWAP, and in an offline mode in the case of global model.

\subsection{Data}

Meteorological outputs and runoff from INMCM4.0's simulations for historical (reference) period (1971-2005) and for two future periods (2026-2045 and 2081-2100), prepared for the phase five of the Coupled Model Intercomparison Project (CMIP5) (Taylor et al., 2012), were used in this study. Projections were performed for two greenhouse gas emission scenarios: a high emissions scenario (RCP8.5) and a medium mitigation scenario (RCP4.5).

Meteorological outputs from INMCM4.0 (precipitation, incoming longwave and shortwave radiation, air temperature and humidity, atmospheric pressure, and wind speed) were used as forcing data to drive the LSM SWAP for runoff simulations. The land surface model parameters for SWAP were prepared using global one-degree datasets provided within the framework of the Global Soil Wetness Project, phase 2 (GSWP-2) (Dirmeyer et al., 2002).

For validation of both models, daily values of streamflow, measured at gauge stations of the rivers (Fig. 1) and kindly provided by Global Runoff Data Centre (GRDC), were used.

\subsection{Calibration}

\subsubsection{SWAP}

Since a set of a priori parameters for the SWAP model is based on global datasets, their values identify the basins very approximately and need optimization. Optimization was performed automatically against measured daily runoff using the Shuffled Complex Evolution algorithm (SCE-UA) developed by Duan et al. (1992). The Nash-Sutcliffe coefficient of efficiency NS (Nash and Sutcliffe, 1970) was used as an objective function. The search of the optimum of the objective function was performed under the condition that the absolute value of systematic error |Bias|, calculated as

$\mid$ Bias $|=| \frac{\sum_{\Omega}\left(x_{\text {sim }}-x_{\text {obs }}\right)}{\sum_{\Omega} x_{\text {obs }}} \mid \cdot 100 \%$

(where $x_{\text {sim }}$ and $x_{\text {obs }}$ are simulated and observed values of a variable $x$ ), does not exceed $5 \%$ (as suggested in Nasonova et al., 2009).

Eight model parameters were calibrated using real meteorological forcing data (as in Gusev et al., 2008). Hereinafter, the obtained optimal values of model parameters will be referred to as OPRM-8 (eight optimal parameters under real meteorology).

To reduce possible systematic errors in meteorological variables four correction factors for the most influencing variables (for shortwave and longwave radiation, and separately for liquid and solid precipitation) were calibrated along with seven model parameters (for details, see Gusev et al., 2008). So, in this case 11 parameters were calibrated. The obtained set of optimal values of model parameters and correction factors will be referred to as OPRM-11.

\subsubsection{INMCM4.0}

Instantaneous runoff, simulated by INMCM4.0, was transformed by a river routing model to obtain streamflow at a river basin outlet. In so doing the effective velocity of water movement in a channel network was manually optimized using daily river runoff measurements.

\subsection{Bias correction in meteorological forcing data}

Since meteorological variables simulated by AOGCM INMCM4.0 contain systematic errors (biases) several approaches were used to correct variables before using them as inputs for SWAP. First, a correction factor for each meteorological variable was computed as the ratio of measured variable, averaged over each river basin and over the reference period, to corresponding simulated value. The correction factors were then applied to the AOGCM-simulated $3 \mathrm{~h}$ meteorological fields (the corrected fields will be referred to as COR1).

The second approach is hybridization of simulated meteorological data with observations following Zao and Dirmeyer (2003). To correct simulated meteorological variables (with the exception of shortwave radiation) the simulations were scaled by the ratios of the monthly mean observed values to the corresponding monthly mean values simulated by AOGCM. For shortwave radiation, when calculated the ratio a diurnal course of radiation was taken into 

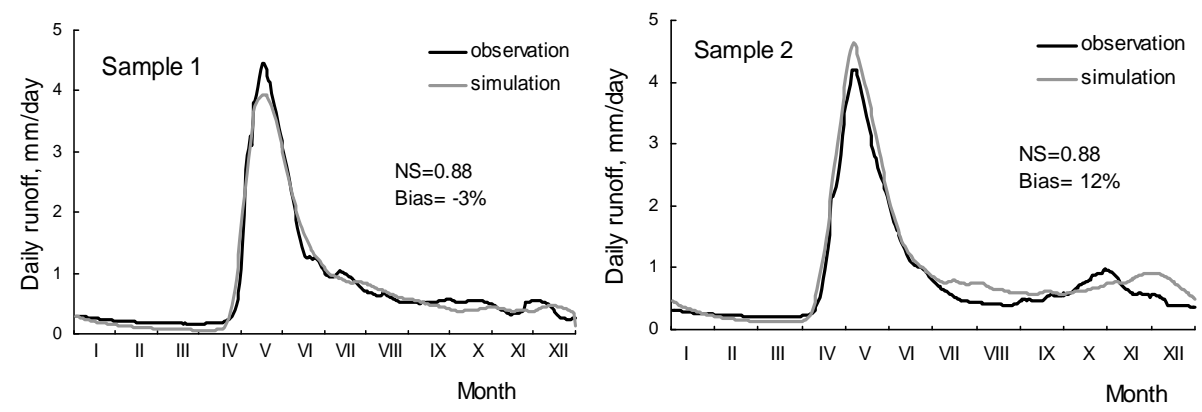

Figure 2. Comparison of measured and simulated by SWAP hydrographs of daily runoff for the Northern Dvina River averaged over the Sample 1 (calibration) and Sample 2 (validation).

account (monthly-3-hourly data were calculated rather than monthly mean values). The corrected 3-hour meteorological fields will be referred to as COR2.

The third approach represents recalibration of SWAP model using meteorological forcing data simulated by AOGCM. The obtained set of optimal values of model parameters and correction factors will be referred to as OPGM11 (11 optimal parameters under GCM's meteorology). One more recalibration of SWAP was performed for hybridized meteorological data COR2. The obtained optimized parameters will be referred to as OPHM-11.

\section{Results}

\subsection{Investigating SWAP model robustness}

In order to make sure that model parameter values, obtained for the current conditions, remain valid in projection periods, SWAP model transposability in time under contracted climate conditions was analyzed before its application for hydrological projections. In so doing, model calibration and validation was performed for contrasted climatic conditions in terms of temperature and precipitation. Here, the Northern Dvina River will be considered. We have chosen five years (hereinafter, referred to as Sample 1) with the lowest annual values of precipitation and air temperature during the reference period. The model parameters were optimized for these years (model simulations were performed for the whole observational period). Then the optimized values of model parameters were used for runoff simulation for seven years (referred to as Sample 2) with the highest annual values of precipitation and air temperature. The difference between mean annual values of air temperature in these two samples was nearly $2{ }^{\circ} \mathrm{C}$, while the difference between annual precipitation was about $15 \%$. Such changes in temperature and precipitation are often projected by the end of XXI century for the pan-Arctic region in different climate change scenarios.

Modeled hydrographs of daily river runoff averaged over the years from the Sample 1 and Sample 2, respectively, are given in Fig. 2. As can bee seen, hydrographs simulated for the Sample 2 using the model parameters optimized for the
Sample 1 are in a good agreement with measured hydrographs. The Nash-Sutcliffe coefficients of efficiency are high for both samples. Bias is greater in the Sample 2, nevertheless, it can be treated as satisfactory.

Thus, it can be concluded that the SWAP model, calibrated for a particular river basin for the driest and coldest years, can be applied with the same optimized parameters in the case of increasing air temperature and precipitation, i.e. the model is rather robust.

\subsection{Simulating historical river runoff by SWAP and INMCM4.0 models}

Table 1 summarizes statistics characterizing how AOGCM INMCM4.0 and LSM SWAP reproduce river runoff during historical periods. Simulations by SWAP were performed using meteorological outputs from INMCM4.0 with and without post-processing bias-correction and with different sets of optimal parameters. As can be seen, recalibration of SWAP's parameters together with correcting factors for precipitation and radiation provided the best results (see OPGM-11 in Table 1) for both rivers. As to INMCM4.0, it showed good results for the Northern Dvina River, while for the Kolyma River the performance was poor (and INMCM4.0 will not be used for hydrological projections for the Kolyma River) due to overestimation of simulated precipitation by $90 \%$.

\subsection{River runoff projections and their uncertainties}

The river runoff projections were obtained for two greenhouse gas emission scenarios: RCP4.5 and RCP8.5 and for two periods: (a) 2026-2045 and (b) 2081-2100. For convenience, they will be referred to as $45 \mathrm{a}$ and $45 \mathrm{~b}$, and $85 \mathrm{a}$ and $85 \mathrm{~b}$. Table 2 summarizes projected relative changes of annual river runoff (normalized by mean annual runoff during the reference period equaled to $294 \mathrm{~mm} \mathrm{yr}^{-1}$ for the Northern Dvina River and to $193 \mathrm{~mm} \mathrm{yr}^{-1}$ for the Kolyma River) simulated by INMCM4.0 and SWAP.

Five river runoff projections were simulated by SWAP. Differences among the projections, obtained for the same scenario and for the same time interval, illustrate uncertain- 
Table 1. Statistical characteristics of river runoff simulations $\left(x_{\text {sim }}\right)$ performed by the LSM SWAP with different sets of optimal parameters and different bias-correction techniques and by the AOGCM INMCM4.0 (NS was calculated for monthly values).

\begin{tabular}{|c|c|c|c|c|c|c|c|}
\hline \multirow[t]{2}{*}{ Statistics } & \multirow[t]{2}{*}{ INM-CM4.0 } & \multicolumn{6}{|c|}{ SWAP } \\
\hline & & OPRM-8 & OPGM-11 & $\begin{array}{r}\text { COR1, } \\
\text { OPRM-8 }\end{array}$ & $\begin{array}{r}\text { COR2, } \\
\text { OPRM-8 }\end{array}$ & $\begin{array}{r}\text { COR2, } \\
\text { OPRM-11 }\end{array}$ & $\begin{array}{r}\text { COR2, } \\
\text { OPHM-11 }\end{array}$ \\
\hline \multicolumn{8}{|c|}{ Northern Dvina River (1972-2003) } \\
\hline$x_{\text {sim }}, \mathrm{mm} \mathrm{yr}^{-1}$ & 284 & 344 & 294 & 275 & 266 & 272 & 284 \\
\hline$x_{\mathrm{sim}} / x_{\mathrm{obs}}$ & 0.97 & 1.17 & 1.00 & 0.94 & 0.90 & 0.93 & 0.97 \\
\hline Bias, $\%$ & -3.8 & 16.8 & 0.1 & -6.4 & -9.9 & -7.8 & -3.6 \\
\hline NS & 0.70 & 0.60 & 0.77 & 0.73 & 0.63 & 0.68 & 0.73 \\
\hline \multicolumn{8}{|c|}{ Kolyma River (1978-1998) } \\
\hline$x_{\mathrm{sim}}, \mathrm{mm} \mathrm{yr}^{-1}$ & 371 & 370 & 200 & 197 & 166 & 165 & 196 \\
\hline$x_{\mathrm{sim}} / x_{\mathrm{obs}}$ & 1.92 & 1.92 & 1.04 & 1.02 & 0.86 & 0.85 & 1.02 \\
\hline Bias, \% & 92.0 & 92.0 & 3.5 & 2.2 & -14.0 & -14.8 & 1.5 \\
\hline NS & -0.20 & -0.46 & 0.64 & 0.63 & 0.57 & 0.57 & 0.62 \\
\hline
\end{tabular}

Table 2. Relative change in annual runoff (\%) of the Northern Dvina and the Kolyma rivers obtained by the LSM SWAP with different sets of optimal parameters and different bias-correction techniques and by the AOGCM INMCM4.0. Mean, maximum and minimum values are given for the SWAP's projections.

\begin{tabular}{|c|c|c|c|c|c|c|c|c|c|c|}
\hline \multirow[t]{2}{*}{ Scenario } & \multirow[t]{2}{*}{ INMCM4.0 } & \multicolumn{9}{|c|}{ SWAP } \\
\hline & & OPGM-11 & $\begin{array}{r}\text { COR1, } \\
\text { OPRM-8 }\end{array}$ & $\begin{array}{r}\text { COR2, } \\
\text { OPRM-8 }\end{array}$ & $\begin{array}{r}\text { COR2, } \\
\text { OPRM-11 }\end{array}$ & $\begin{array}{r}\text { COR2, } \\
\text { OPHM-11 }\end{array}$ & Mean & Min & $\operatorname{Max}$ & $\begin{array}{c}\Delta= \\
\max -\min \end{array}$ \\
\hline \multicolumn{11}{|c|}{ Northern Dvina River } \\
\hline $45 \mathrm{a}$ & 0.6 & 1.1 & -0.3 & 1.6 & 0.6 & 1.6 & 0.9 & -0.3 & 1.6 & 1.9 \\
\hline $45 b$ & 8.5 & 18.2 & 14.3 & 17.3 & 13.4 & 17.9 & 16.2 & 13.4 & 18.2 & 4.8 \\
\hline $85 \mathrm{a}$ & 4.0 & 10.0 & 8.3 & 9.8 & 8.1 & 10.3 & 9.3 & 8.1 & 10.3 & 2.2 \\
\hline $85 b$ & 10.6 & 26.3 & 20.4 & 24.0 & 19.0 & 27.2 & 23.4 & 19.0 & 27.2 & 8.2 \\
\hline \multicolumn{11}{|c|}{ Kolyma River } \\
\hline $45 \mathrm{a}$ & - & 1.4 & 2.8 & 3.9 & 5.8 & 5.4 & 3.9 & 1.4 & 5.8 & 4.4 \\
\hline $45 b$ & - & 13.9 & 13.5 & 15.1 & 19.3 & 17.9 & 15.9 & 13.5 & 19.3 & 5.8 \\
\hline $85 \mathrm{a}$ & - & -0.1 & 0.1 & 0.7 & 2.2 & 1.3 & 0.8 & -0.1 & 2.2 & 2.3 \\
\hline $85 \mathrm{~b}$ & - & 25.6 & 25.7 & 25.4 & 30 & 31.7 & 27.7 & 25.4 & 31.7 & 6.3 \\
\hline
\end{tabular}

ties resulted from the application of different bias-correction techniques for meteorological forcing data. As can be seen from the Table 2, differences among SWAP's projections are rather small and do not exceed $8.2 \%$ for both rivers. Differences between projections from two models are larger. Both models project an increase in river runoff for the Northern Dvina River, however, SWAP's projections are nearly twice larger than corresponding projections form INMCM4.0.

\section{Conclusions}

The ability of LSM SWAP and AOGCM INMCM4.0 to reproduce runoff of the Northern Dvina and the Kolyma rivers was investigated. AOGCM INMCM4.0 performs fairly well for the Northern Dvina River, while for the Kolyma the re- sults are very poor. As to SWAP, application of optimal parameter values obtained for real meteorology does not provide a good accuracy of streamflow simulation (especially for the Kolyma River) when meteorological outputs from AOGCM drive the model. Application of bias-correction techniques for AOGCM's meteorology provides better agreement between simulated and measured river runoff.

Due to non-stationary nature of climate the SWAP model robustness was investigated before its application for hydrological projections. It was shown that SWAP is quite robust and can be applied for climate change studies.

Several river runoff projections up to 2100 were obtained with the help of SWAP and INMCM4.0 for two greenhouse gas emission scenarios: RCP8.5 and RCP4.5. Scatter among SWAP's projections due to application of different bias- 
correction techniques is fairly small (does not exceed $8 \%$ ), while differences between changes in runoff projected by two models are larger. On the average, SWAP produces increase in runoff for the Northern Dvina River twice larger than INMCM4.0.

Acknowledgements. The study was supported by the Russian Science Foundation (grant No. 14-17-00700).

\section{References}

Arora, V., Seglenieks, F., Kouwen, N., and Soulis, E.: Scaling aspects of river flow routing, Hydrol. Process., 15, 461-477, 2001.

Arora, V. K. and Boer, J.: Effects of simulated climate change on the hydrology of major river basins, J. Geophys. Res., 106, 33353348, 2001.

Dirmeyer, P., Gao, X., and Oki, T.: The Second Global Soil Wetness Project. Science and Implementation Plan, IGPO Publication Series, International GEWEX Project Office, Silver Spring, 37, 1-75, 2002.

Duan, Q., Sorooshian, S., and Gupta, V. K.: Effective and efficient global optimization for conceptual rainfall runoff models, Water Resour. Res., 28, 1015-1031, 1992.

Gosling, S. N., Taylor, R. G., Arnell, N. W., and Todd, M. C.: A comparative analysis of projected impacts of climate change on river runoff from global and catchment-scale hydrological models, Hydrol. Earth Syst. Sci., 15, 279-294, doi:10.5194/hess-15279-2011, 2011.

Gusev, E. M. and Nasonova, O. N.: Simulation of heat and water exchange at the land-atmosphere interface on a local scale for permafrost territories, Euras. Soil Sci., 37, 1077-1092, 2004.

Gusev, E. M. and Nasonova, O. N.: Modelling heat and water exchange between the land surface and the atmosphere, Nauka, Moscow, 2010.

Gusev, E. M., Nasonova, O. N., Dzhogan, L. Y., and Kovalev, E. E.: The Application of the land surface model for calculating river runoff in high latitudes, Water Resources, 35, 171-184, 2008.
Gusev, Y. M. and Nasonova, O. N.: Modelling heat and water exchange in the boreal spruce forest by the land-surface model SWAP, J. Hydrol., 280, 162-191, 2003.

Kanae, S., Nishio, K., Oki, T., and Musiake, K.: Hydrograph estimations by flow routing modeling from AGCM output in major basins of the world, Annu. J. Hydraul. Eng., 39, 97-102, 1995.

Liston, G. E., Sud, Y. C., and Wood, E. F.: Evaluatig GCM land surface hydrology parameterizations by computing river discharges using a runoff routing model: Application to the Mississippi Basin, J. Appl. Meteorol., 33, 394-405, 1994.

Miller, J. R. and Russell, G. L.: The impact of global warming on river runoff, J. Geophys. Res., 97, 2757-2764, 1992.

Nash, J. E. and Sutcliffe, J. V.: River flow forecasting through conceptual models: 1 A discussion of principles, J. Hydrol., 10, 282$290,1970$.

Nasonova, O. N., Gusev, Y. M., and Kovalev, Y. E.: Investigating the ability of a land surface model to simulate streamflow with the accuracy of hydrological models: A case study using MOPEX materials, J. Hydrometeorol., 10, 1128-1150, 2009.

Nohara D., Kiton, A., Hosaka, M., and Oki, T.: Impact of Climate change on river discharge projected by multimodal ensemble, J. Hydrometeorol., 7, 1076-1089, 2006.

Oki, T. and Sud, Y. C.: Design of Total Runoff Integrating Pathways (TRIP) - A global river channel network, Earth Interact., 2, 1-37, 1998.

Taylor, K. E., Stouffer, R. J., and Meehl, G. A.: An Overview of CMIP5 and the experiment design, B. Am. Meteorol. Soc., 93, 485-498, 2012.

Volodin, E. M., Diansky, N. A., and Gusev, A. V.: Simulating present-day climate with the INMCM4.0 coupled model of the atmospheric and oceanic general circulations, Izvestiya, Atmos. Ocean. Phys., 46, 414-431, 2010.

Zhao, M. and Dirmeyer, P.: Production and Analysis of GSWP-2 near-surface meteorology data sets, COLA Techn. Rep., 159, 1$38,2003$. 